\title{
Application of Water Height Puddles Based on Android and Arduino
}

\author{
Ahmad Rifai', Rahmat Izwan Heroza², Sarmayanta Sembiring ${ }^{3}$, Rossi \\ Passarela ${ }^{4}$, Alfarisi $^{5}$
}

Faculty of Computer Science, Universitas Sriwijaya, Indonesia

\begin{abstract}
Information about the elevation of water on the road is an essential thing to know. Such information can be a preliminary warning about the resulting negative impact that an application can display that information. The developed application gets input from sensors and Arduino to display the data related to the altitude of a puddle. This app is made based on Android so that app users can interact easily. Application development has three stages that are the development of hardware for sensors that will provide input to the application, software development in the form of Android-based applications to display data from the sensor accompanied by integration Both systems. The resulting application can display the information of flood altitude on the map based on the specified marker that is red for water height above $50 \mathrm{~cm}$, yellow for water height between $20 \mathrm{~cm}$ to $50 \mathrm{~cm}$, and green for water height Taken $20 \mathrm{~cm}$.
\end{abstract}

Keywords: puddle, mobile applications, Android, Arduino, sensors

\section{INTRODUCTION}

High rainfall intensity for a long time can result in a reasonably high water puddle on the road, causing congestion. These conditions lead to road users having to find alternative avenues to avoid congestion [1].

Therefore, to minimize the occurrence of congestion, it is necessary information appropriate and appropriate. With the development of technology now allows information can be accessed anytime or anywhere. Technology moves into one of the technologies that can transmit and receive information over the Internet. Android is the wrong operating system used on the mobile device. Android has many features that allow users to access information quickly and precisely

Development of Android-based mobile app allows us to get information quickly depending on the infrastructure owned. The infrastructure consists of network, equipment and information systems [2]. Available features allow the development of mobile apps to display information in text, image or video form in real-time.

In this research conducted the development of a moving application prototype to store and display information on the altitude of a puddle. The application retrieves data from the server where the server receives data from the sensors placed on the water-prone areas. Application development is using Android because of the ease in obtaining information anywhere and anytime as well and Arduino to get water altitude data from sensors used.

\section{GENERAL DEFINITION}

\section{Mobile Application}

Current moving applications are needed because telecommunication tools that are scattered around the world need applications that can quickly work their users wherever and whenever especially in terms of information. The app is accessible via wireless devices such as pagers, such as mobile phones and PDAs.

\section{Application}

According to Buyen [2], an application is a unit of software created to serve the needs of several activities. Examples include company software, accounting software, office buildings, graphics software and media players. Application is a software that functions to perform various forms of work 
or specific tasks such as application, use and addition of data. The application program is a ready-made program - programs designed to carry out a function for other users or applications. Examples of applications are word processing programs and Web browsers. The application will use the computer's operating system (OS) and other supporting applications.

Application classification consists of two namely

1. Specialist software applications, programs with integrated documentation designed to carry out specific tasks.

2. Package applications, with bundled documentation designed for certain types of problems.

\section{Mobile}

Mobile is a smooth move from one place to another, such as a mobile phone means that a phone terminal that can easily switch from one place to another without interruption or disconnection Communication.

\section{Characteristics of Mobile Devices}

Mobile devices have many types in terms of size, design and layout. However, they have similar characteristics that are very different from desktop systems, which include: a) Mobile devices have a small size. Consumers want the smallest devices for their comfort and mobility. b) Mobile devices also have small memory, namely primary (RAM) and secondary (disk). This limitation is one of the factors that influence program writing for various types of these devices. With a limited amount of memory, special considerations must be taken to maintain the use of this expensive resource. c) Limited process power, mobile system is not as powerful as their counterpart desktop. Size, technology and cost are some of the factors that influence the status of these resources. Like the hard disk and RAM has a size that fits with a small package. d) Low power consumption, mobile devices use less power compared to desktop machines. These devices must save power because they run in conditions where the power supplied is limited by batteries. e) Robust and reliable, as mobile devices are always carried anywhere, they must be strong enough to face the collisions, movements and occasional drops of water droplets. f) Limited connectivity, mobile devices have low bandwidth; some of them are not even connected. Most of them use wireless connections. g) Short life spans, these consumer devices ignite in seconds most of them are always on. Try to take the case of a handphone, they boot in seconds, and most people do not turn off their handphone even at night.

According to Buyen, The mobile app comes from the Word application Application, which means implementation, application, use. The app's term is a ready-made program designed to perform a function for another user or application. The intended target can use it while the mobile can be interpreted as a move from place to place Other. The free word means to move or move, so mobile application, according to Rangsang Purnama [3] is a designation for applications running on the mobile device. By using the mobile application, can easily perform various activities ranging from entertainment, selling, learning, doing office work, and browsing. The use of mobile applications for entertainment is most used by mobile phone users, because by utilizing the features of the game, music player, until the video player makes us easier to enjoy entertainment anytime and anywhere. Mobile devices have many types in terms of size, Desai layouts. However, it has a very different characteristic in stock from the desktop system. Mobile devices have a small memory.

\section{Android}

Android is a Linux-based operating system developed on smartphone and tablet devices. Android is open where developers can create applications for various mobile devices. Android operating system based on Java makes many software developers switch and develop applications based on Android. Android features such as Browser, Multimedia Messaging Service, Short Message Service, Global Positioning System and integrated sensors make it easy for users to know the information, position quickly and also communicate. 


\section{METHODOLOGY}

a. Making System Architecture

Figure 1 shows the system architecture in this application. This architecture consists of components, namely measuring devices, Arduino systems, solar panels, client applications. The measurement tool is used to measure the height of a puddle; the Arduino system is used to send data from the measuring instrument to the server via the GSM module, the solar panel is used to supply power to Arduino and users in the form of a client application used to display information.

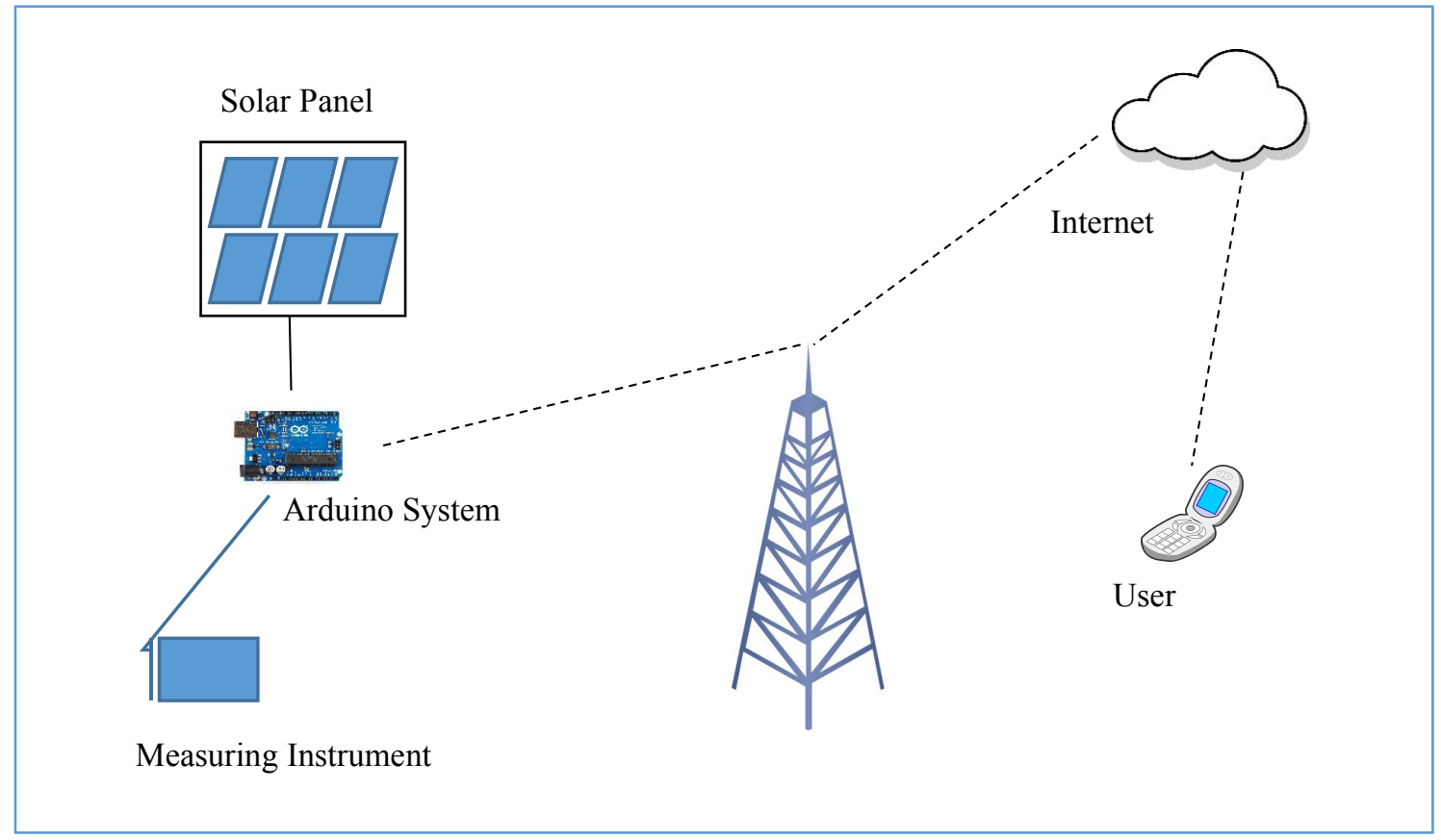

Figure 1 Architecture System

b. Arduino Module Creation

1. Ultrasonic Module

The module is a proximity sensor that is used to measure the height of the water, as shown in Figure 2. Measurement limits that can be used by sensors ranging from $3 \mathrm{~cm}$ to $400 \mathrm{~cm}$ [5].

The output from this module will be sent to the Arduino Uno module for processing.

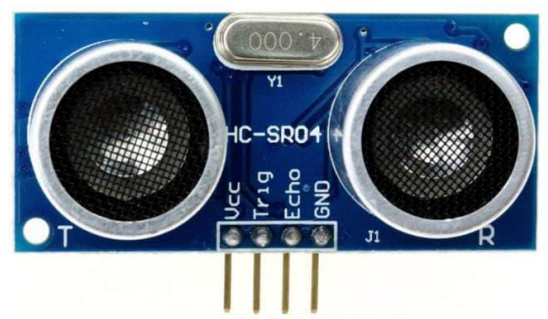

Figure 2 Ultrasonic Modul

2. Arduino Module

Arduino Uno is an ATmega328P based microcontroller. This module consists of 14 pins for input/output, 6 of which can be used as PWM outputs), six analogue inputs, $16 \mathrm{MHz}$ quartz crystal, USB connection, a power jack, ICSP header, and reset button [6]. This module is used to get data from the ping sensor; then the data will be sent to the server via the A6 GSM / GPRS module. Figure 3 shows the Arduino module used. 


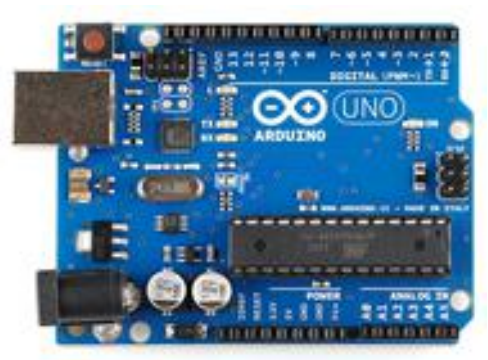

Figure 3 Arduino Module

\section{A6 GSM/GPRS Module}

The A6 GSM / GPRS module used to communicate wirelessly has data transfer speeds of up to $85.6 \mathrm{Kbps}$ (downlink) / $42.8 \mathrm{Kbps}$ (uplink). This module can work in 4 network mode bands, namely 850/900/1800/1900 MHz. The GPRS module used can be seen in Figure 4.

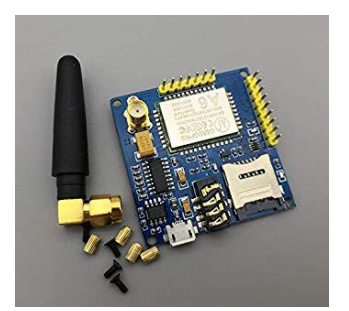

Figure 4 GPRS Module

c. Application Making

Resulting Data flow diagram can be seen in Figure 5. Two entities are user and module sensors where the user entity sends data location and Entity sensor module providing data of water height.

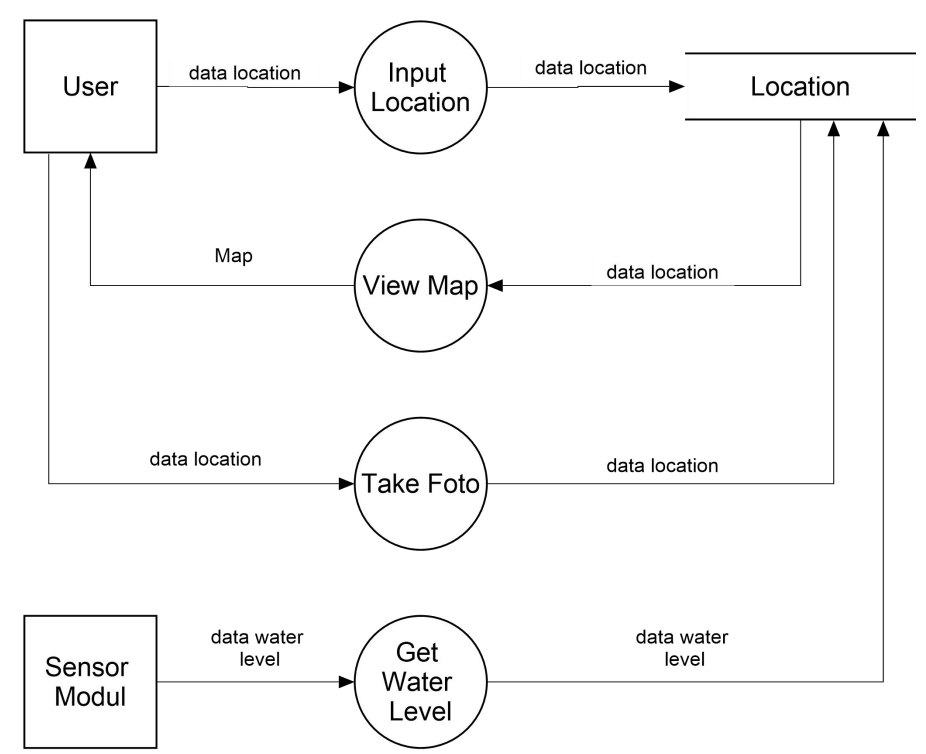

Figure 5 Data Flow Diagram

The application design has features for entering sensor location data and displaying it on a map. Application Form Design can be seen in Figure 6. 


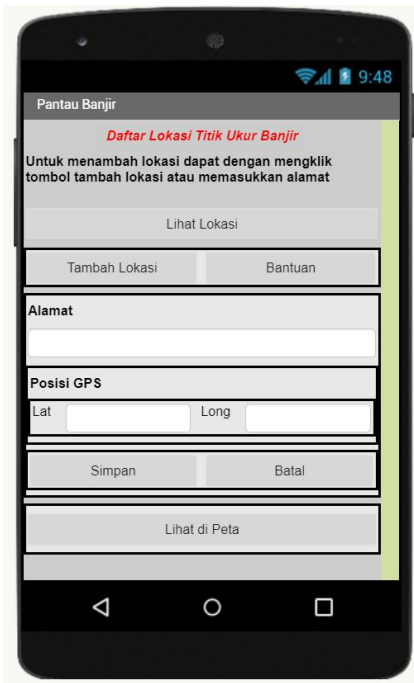

Figure 6 Application Form Design

\section{RESULTS AND DISCUSSION}

The resulting application (figure 7) has several features such as features to add sensor locations (figure 8), view a list of locations (figure 9) and display on a map. The flood sensor location is added by entering the location name, latitude coordinates and longitude coordinates (figure 8). Location 1 is determined by latitude coordinates which is -2.965292 and longitude coordinates are 104.802193 . Location 2 is determined at latitude coordinates -2.984289 , and longitude coordinates 104.731895 .

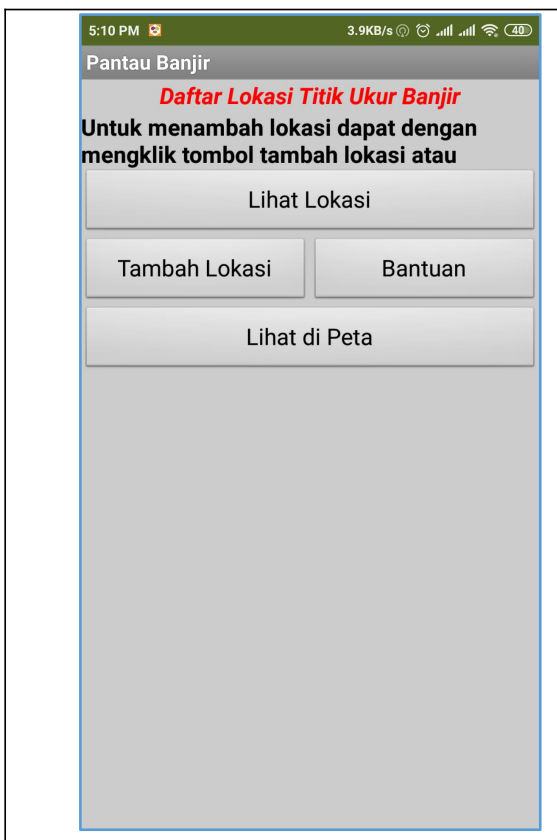

Figure 7 Mobile Application

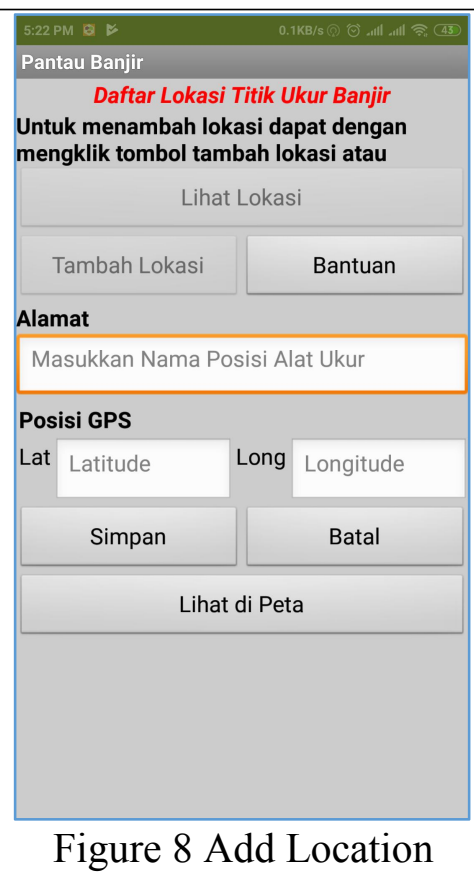

Figure 9 List of Location

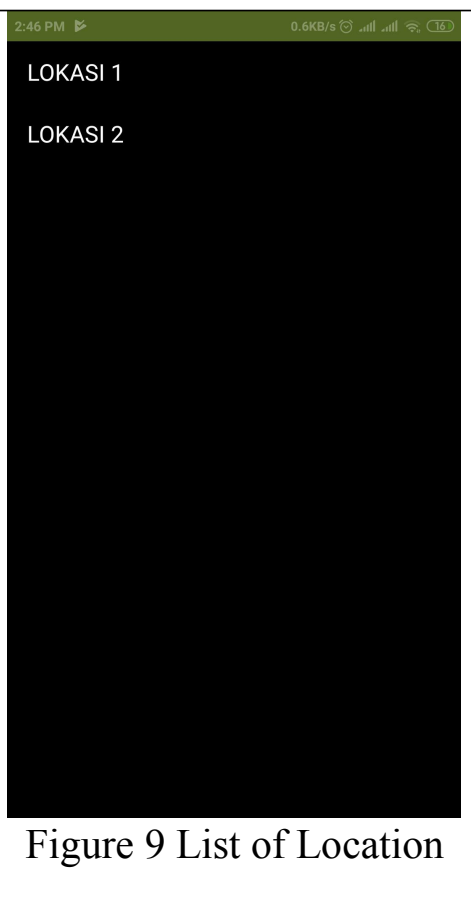

Tests are carried out at both locations in a predetermined location list. In this test has several scenarios, namely scenario 1 , the condition of water level below $20 \mathrm{~cm}$, scenario 2 , the condition of water level between $20 \mathrm{~cm}$ to $50 \mathrm{~cm}$, and scenario 3 for water conditions under $50 \mathrm{~cm}$. For the first scenario, the colour of the mark on the map is green; this means that the height of the water is below $20 \mathrm{~cm}$, where the height of the puddle made is as high as $5 \mathrm{~cm}$. The second scenario, setting the height of the puddle is $30 \mathrm{~cm}$, the map in the application displays marking in yellow and the third scenario, setting the height of the puddle to $60 \mathrm{~cm}$, marking on the map has a red colour. The results of this test can be seen in Figures 10, 11 and 12. 


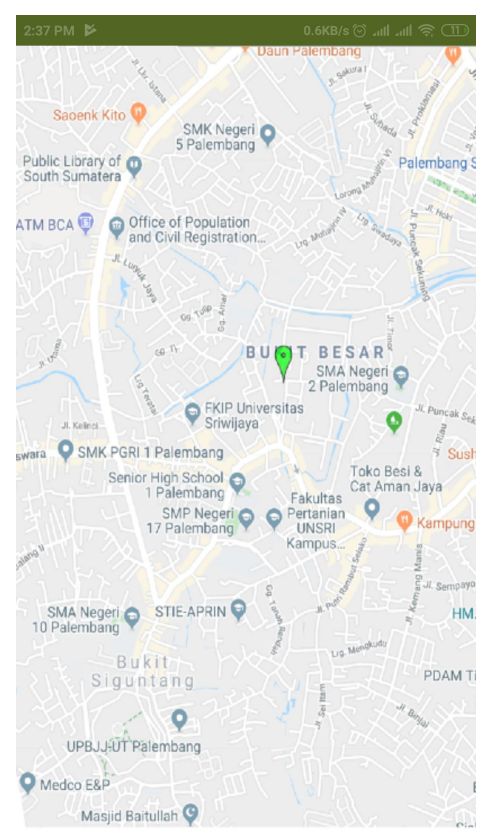

Figure 10 Green Marker on Map

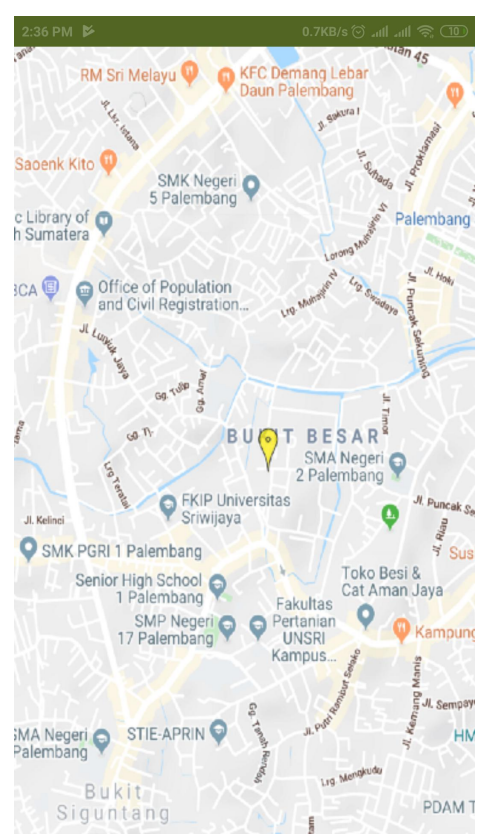

Figure 11 Yellow Marker on Map

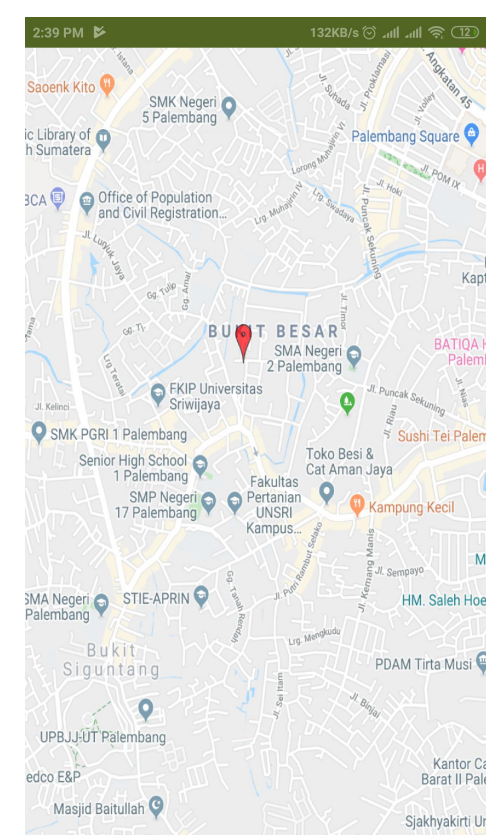

Figure 12 Red Marker on Map

\section{CONCLUSION}

Applications produced in this study can display information based on the height of a puddle with red, yellow and green markers where the height of the puddle is above $50 \mathrm{~cm}$, between $20 \mathrm{~cm}$ to $50 \mathrm{~cm}$ and below $50 \mathrm{~cm}$. The information generated is obtained based on data from measuring instruments.

\section{REFERENCES}

[1] TRIBUNSUMSEL.COM, "Ini Wilayah Macet Parah dan Banjir di Palembang Rabu (28/11/2018) Sore Ini, Cari Jalan Alternatif," 2811 2018. [Online]. Available:

https://sumsel.tribunnews.com/2018/11/28/ini-wilayah-macet-parah-dan-banjir-di-palembang-r abu-28112018-sore-ini-cari-jalan-alternatif. [Accessed 1210 2019].

[2] U. Essays, "Literature Review On Mobile Apps Information Technology Essay," 1 April 2019. [Online]. Available:

https://www.ukessays.com/essays/information-technology/literature-review-on-mobile-apps-in formation-technology-essay.php.

[3] J. Buyens, Web Database Development, Jakarta: Elex Media Komputindo, 2001.

[4] R. Purnama, Mari Mengenal J2ME Java 2 Micro Edition, Jakarta: Prestasi Pustaka, 2010.

[5] Arduino, "Ping Ultrasonic Range Finder," 297 2015. [Online]. Available: https://www.arduino.cc/en/tutorial/ping. [Accessed 1210 2019].

[6] Arduino, "Getting Started with Arduino and Genuino UNO," Arduino, 121 2017. [Online]. Available: https://www.arduino.cc/en/Guide/ArduinoUno\#toc8. [Accessed 1210 2019]. 